\title{
Patient Preferences About Organ Offers in Liver Transplantation
}

Received September 29, 2014; accepted September 30, 2014.

\section{TO THE EDITORS:}

I read with interest the article entitled "Shared Decision Making in Transplantation: How Patients See Their Role in the Decision Process of Accepting a Donor Liver" by Dries et al. ${ }^{1}$ in the September issue of Liver Transplantation. I thank the authors for confirming our prior findings published in this journal in 2011. ${ }^{2}$ The conclusions of the 2 studies are remarkably congruous: most patients prefer an active role in decisions about organ acceptance, and although many are initially risk-averse, this tendency can be mitigated if they are reminded of the competing risk of waiting-list mortality. This consistency in preferences between patient populations at 2 different centers on different continents lends support to the generalizability of the message. It was surprising, however, that our 2011 study was not cited. The authors incorrectly state that "this is the first study revealing the opinions of liver patients on these issues."

In their Discussion section, the authors mention that the use of standardized educational tools might allow patients to participate more in shared decision making about organ offers. We agree, and for this reason, we have developed and pilot-tested a Web-based patient educational tool; this work was also published in Liver Transplantation earlier this year. ${ }^{3}$ We found that the tool improved patient knowledge and increased patient willingness to consider higher risk organs. This tool is available online for any center to use at http://www.liver-donor-quality.com/start/ ?next $=/$. We welcome feedback and collaboration on ways to help to satisfy patient preferences to be involved in organ acceptance decisions.

Michael L. Volk, M.D., M.Sc. Division of Gastroenterology and Hepatology University of Michigan Health System Ann Arbor, MI

\section{REFERENCES}

1. Dries SO, Annema C, Berg AP, Ranchor AV, Porte RJ. Shared decision making in transplantation: how patients see their role in the decision process of accepting a donor liver. Liver Transpl 2014;20:1072-1080.

2. Volk ML, Tocco RS, Pelletier SJ, Zikmund-Fisher BJ, Lok AS. Patient decision making about organ quality in liver transplantation. Liver Transpl 2011;17:1387-1393.

3. Volk ML, Roney M, Fagerlin A. Pilot test of a patient decision aid about liver transplant organ quality. Liver Transpl 2014;20:850-855. 